\title{
Demography, Pattern of Care, and Survival in Patients with Xanthoastrocytoma: A Systematic Review and Individual Patient Data Analysis of 325 Cases
}

\author{
Supriya Mallick ${ }^{1}$ Prashanth Giridhar $^{1}$ Rony Benson ${ }^{1}$ \\ ${ }^{1}$ Department of Radiation Oncology, B.R.A. Institute-Rotary Cancer \\ Hospital, All India Institute of Medical Sciences, New Delhi, India
}

\begin{abstract}
Address for correspondence Rony Benson, Department of Radiation Oncology, B.R.A. Institute-Rotary Cancer Hospital, All India Institute of Medical Sciences, New Delhi, India (e-mail: ronybenson@gmail.com).
\end{abstract}

\begin{abstract}
Keywords

- meta-analysis

- survival

- xanthoastrocytoma

Objectives Xanthoastrocytoma (XA) is a low-grade glial tumor seen in young adults, and there is lack of robust data on treatment of this rare tumor. In this systematic review and individual patient's data analysis, we aimed to look into the demography, pattern of care, survival outcomes, and prognostic factors in patients with both Grade II and III XA.

Methods A comprehensive search was conducted with the Medical Subject Heading terms: "Xanthoastrocytoma; Pleomorphic Xanthoastrocytoma; Anaplastic Xanthoastrocytoma; Xanthoastrocytoma AND treatment; and Anaplastic Xanthoastrocytoma AND survival" to find all possible publications.

Results A total of 325 individual patients from a total of 138 publications pertaining to XA were retrieved. Median age of the entire cohort was 19 years. About $56.1 \%$ of the patients underwent a gross total resection (GTR) and 31.4\% underwent a subtotal resection. Nearly, $76.6 \%$ of the patients had a Grade II tumor and adjuvant radiation was delivered in $27.4 \%$ of the patients. Estimated 2- and 5-year progression-free survival (PFS) were 68.5 and $51.2 \%$, respectively. Age, grade, and extent of surgery were significant factors affecting PFS. Estimated 2- and 5-year overall survival (OS) was 88.8 and 78\%, respectively. The median OS for Grade II and Grade III tumors were 209 and 49 months, respectively. Age and extent of surgery were significant factors affecting OS.

Conclusion $X A$ is a disease of young adults with favorable prognosis. Younger patients ( $<20$ years), patients who undergo a GTR, and patients with a lower grade tumor have a better treatment outcome.
\end{abstract}

\section{Introduction}

Xanthoastrocytoma (XA) was first described by Kepes et al in 1979 as a low-grade glial tumor seen in young adults. XA usually presents with seizures and includes Grade II and Grade III tumors with distinct clinical behavior. Though most of the tumors are reported to arise from temporal lobe, these tumors have been reported to arise from any part of the central nervous system. Maximal safe surgical resection is often considered the cornerstone of therapy. Adjuvant therapy though advocated by many lacks consensus and merits a relook. However, the greatest limitation is the sporadic reporting of XA in the literature. In the absence of robust data, treatments are often based on local expertise and institutional protocol extrapolating data of other common glial tumors. Our earlier analysis was limited to patients of Grade II XA. ${ }^{1}$ In this systematic review and individual patient's data analysis, we aimed to look into the demography, pattern of care, survival outcomes, and prognostic factors in patients with both Grade II and III XA. 


\section{Methods}

\section{Search Methodology}

A comprehensive search was conducted in the PubMed, Google Scholar with the Medical Subject Heading terms: "Xanthoastrocytoma; Pleomorphic Xanthoastrocytoma; Anaplastic Xanthoastrocytoma; Xanthoastrocytoma AND treatment; and Anaplastic Xanthoastrocytoma AND survival" to find all possible publications. After retrieving the titles of such articles, we sorted out any unrelated articles. We retrieved full-length articles of those remaining to finalize articles for data extraction. In addition, we searched the references in those articles as well to fetch any article missing after the search. Thereafter, duplicates were removed, and the remaining articles were looked into detail. Patient data were extracted and entered in a predesigned excel chart with the headings of "age, gender, presenting complaints, type of surgery, radiation use, chemotherapy, recurrence, duration of progression-free interval, salvage treatment, death, and survival." Articles that did not report treatment and outcome were excluded from the analysis. Once the data extraction was complete, it was rechecked by the individual authors to look for errors or duplication. A total of 138 articles were retrieved pertaining to XA with 325 patients. ${ }^{138}$ The Preferred Reporting Items for Systematic Reviews and Meta-Analyses flowchart ( - Fig. 1) explains the data synthesis from the eligible studies.

\section{Statistical Analysis}

The data were analyzed and categorical variables were summarized by frequency and percentage and quantitative variables by the median and range. Progression-free survival (PFS) and overall survival (OS) were calculated from the date of diagnosis to the date of documented progression or death. Kaplan-Meier method was used to for survival analysis.

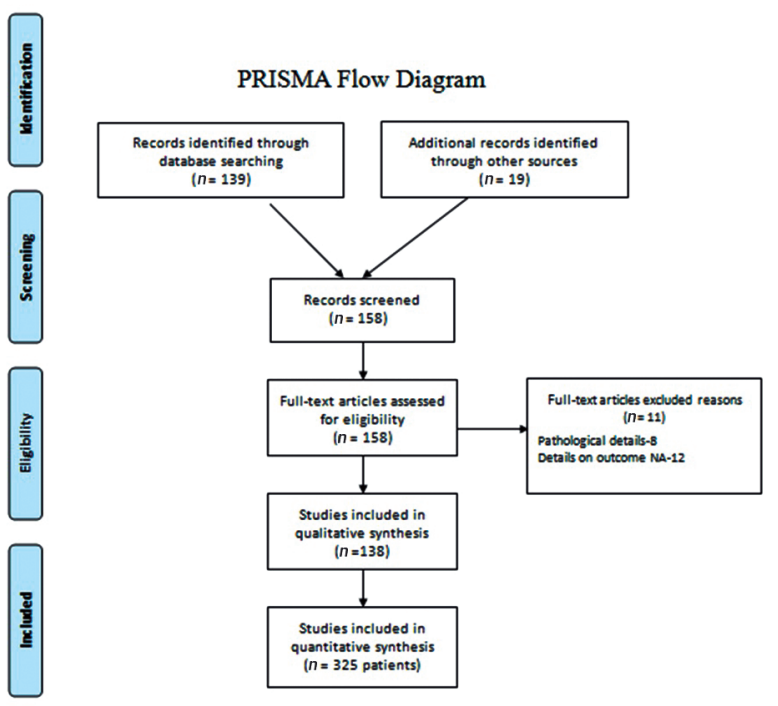

Fig. 1 PRISMA flowchart showing summary of the search methodology and data collection for the meta-analysis. PRISMA, Preferred Reporting Items for Systematic Reviews and Meta-Analyses.
Univariate analysis was performed using log-rank test, and Cox regression model was used for multivariate analysis. Factors with $p$-value $<0.1$ were included in the multivariate analysis. A $p$-value $<0.05$ was taken as significant. SPSS v.16 (SPSS Inc., Released 2007, SPSS for Windows, Version 16.0, Chicago, Illinois, United States) was used for all statistical analysis.

\section{Results}

We retrieved data of 325 individual patients from a total of 138 publications pertaining to XA. Median age of the entire cohort was 19 years (range: $0.9-84$ years). More than fourfifth (82\%) of the patients were diagnosed within the fourth decade. Of these 325 patients, incidence of XA was equally distributed among males and females with a ratio of 0.92:1 favoring females. Nearly half of the patients presented with features of raised intracranial pressure $(47 \%)$ followed by seizure which was the presenting symptom in one-third of the patients. Out of 325 patients, 118 (36.3\%) patients had tumor located in the temporal lobe only followed by multilobar (16\%) disease and frontal lobe (9.8\%). A total of 8 patients had tumor located in different parts of the spinal cord as well. Only two patients had leptomeningeal dissemination at diagnosis. Patient characteristics are summarized in - Table 1.

\section{Treatment}

Surgical details were available in 287 cases. Of these, 161 (56.1\%) patients underwent a gross total resection (GTR) and $90(31.4 \%)$ patients underwent a subtotal resection. Histologic grade was available in 218 cases. Of these, 167 (76.6\%) patients had a Grade II tumor and the remaining $23.4 \%$ patients had a Grade III tumor. Median $\mathrm{K}_{\mathrm{i}}-67$ was found to be $5.6 \%$ (range: $1-33.2 \%$ ). In 14 patients (58.3\%) out of 24 available cases, BRAF mutation was noted. Adjuvant radiation was delivered in $77(27.4 \%)$ patients, whereas 1 patient was treated with palliative radiation and salvage radiation was used in $19(6.8 \%)$ patients. In the available reports, all patients received local radiation alone. Adjuvant chemotherapy was used in 37 (14.9\%) patients. Chemotherapy regimen varied widely; but in the recent report, temozolomide has been found to be the preferred choice $(n=7)$.

\section{Survival Outcome}

Estimated 2- and 5-year PFS were 68.5 and 51.2\%, respectively. In univariate analysis, younger patients ( $\leq 20$ years) found to have better PFS compared with elder patients (> 20 years) (hazard ratio [HR] 2.26 [95\% confidence interval [CI]: 1.3-4.0], $p=0.006$ ). Patients with a GTR had a significantly better PFS than those treated with a subtotal resection (STR) only (HR 2.19 [95\% CI: 1.1-4.2], $p=0.019$ ). PFS was found to be significantly better for those with a Grade II tumor compared with those with a Grade III tumor (HR 3.18 [95\% CI: 1.6-6.4], $p=0.001$ ) ( - Fig. 2). Age, grade, and extent of surgery continued to be significant in multivariate analysis with HR of 1.9 (95\% Cl: 1.2-8.2, $p=0.007$ ), 2.0 (95\% Cl: $1.2-$ $3.3, p=0.005)$, and $1.9(95 \% \mathrm{Cl}: 1.1-3.2, p=0.018)$, respectively. 
Table 1 Demographic features and patterns of care in patients with pleomorphic xanthoastrocytoma

\begin{tabular}{|c|c|}
\hline Patient characteristics & Number of patients (percentage)/(range) \\
\hline Age & Median: 19 y (range: 0.9-84) \\
\hline $\operatorname{Sex}(n=318)$ & $\begin{array}{l}\text { Male: } 153 \\
\text { Female: } 165 \\
\text { Male:female ratio: } 0.93: 1\end{array}$ \\
\hline $\begin{array}{l}\text { Presenting symptoms } \\
(n=229)\end{array}$ & $\begin{array}{l}\text { Seizure: } 108(47.2 \%) \\
\text { Headache: } 76(33.2 \%) \\
\text { Sensory symptoms: } 26(11.4 \%) \\
\text { Motor symptoms: } 16(6.9 \%) \\
\text { Hemorrhage: } 3(1.3 \%)\end{array}$ \\
\hline \multirow[t]{2}{*}{$\begin{array}{l}\text { Radiological feature } \\
(n=61)\end{array}$} & $\begin{array}{l}\text { Cystic: } 44(72.1 \%) \\
\text { Solid: } 10(16.4 \%) \\
\text { Solid-cystic: } 7(11.5 \%)\end{array}$ \\
\hline & Contrast enhancement: 35(57.3\%) \\
\hline $\mathrm{K}_{\mathrm{i}}-67$ labeling index $(n=54)$ & Median: 5.6\% (range: 1-33.2\%) \\
\hline $\begin{array}{l}\text { Surgery } \\
(n=287)\end{array}$ & $\begin{array}{l}\text { Gross total or near total resection: } 161(56.1 \%) \\
\text { Subtotal resection or debulking: } 90(31.4 \%) \\
\text { Biopsy: } 6(2.1 \%)\end{array}$ \\
\hline $\begin{array}{l}\text { Grade } \\
(n=218)\end{array}$ & $\begin{array}{l}\text { Grade II: } 167 \text { (76.6\%) } \\
\text { Grade III: } 51 \text { (23.4\%) }\end{array}$ \\
\hline $\begin{array}{l}\text { BRAF mutation } \\
(N=24)\end{array}$ & $\begin{array}{l}\text { Yes: } 14(58.3 \%) \\
\text { No: } 10(41.7 \%)\end{array}$ \\
\hline $\begin{array}{l}\text { Radiation } \\
(N=281)\end{array}$ & $\begin{array}{l}\text { Adjuvant radiation: } 77(27.4 \%) \\
\text { No adjuvant radiation: } 184(65.5 \%) \\
\text { Palliative: } 1(0.3 \%) \\
\text { Salvage RT: } 19(6.8 \%)\end{array}$ \\
\hline $\begin{array}{l}\text { Chemotherapy } \\
(N=249)\end{array}$ & $\begin{array}{l}\text { Adjuvant: } 37(14.9 \%)(T M Z, n=7) \\
\text { Not used: } 208(83.5 \%) \\
\text { Salvage-4 }(1.6 \%)\end{array}$ \\
\hline $\begin{array}{l}\text { Salvage treatment } \\
(N=76)\end{array}$ & $\begin{array}{l}\text { Surgery: } 20(26.3 \%) \\
\text { Radiation: } 13(17.1 \%) \\
\text { Chemotherapy: } 2(2.6 \%) \\
\text { Surgery + RT: } 13(17.2 \%) \\
\text { CT + RT: } 7(9.2 \%) \\
\text { Surgery + CT: } 3(3.9 \%) \\
\text { Surgery + RT + CT: } 18(23.7 \%)\end{array}$ \\
\hline
\end{tabular}

Abbreviations: $\mathrm{CT}$, chemotherapy; RT, radiotherapy; TMZ, temozolomide.

Estimated 2- and 5-year OS were 88.8 and 78\%, respectively. In univariate analysis, younger patients ( $\leq 20$ years) were found to have better OS compared with elder patients ( $>20$ years) (HR 1.58 [95\% CI: 1.07-2.32], $p=0.019$ ). Patients with a GTR had a significantly better OS than those treated with a STR only (HR 1.72 [95\% CI: 1.1-2.71], $p=0.017$ ). OS was found to be significantly better for those with a Grade II tumor compared with those with a Grade III tumor (HR 2.2 [95\% CI: 1.4-3.6], $p=0.001$ ) ( - Fig. 3). The median OS for Grade II and Grade III tumors were 209 and 49 months, respectively. The other factors such as sex, adjuvant chemotherapy, and adjuvant radiotherapy had no impact on OS. Age and extent of surgery continued to be significant in multivariate analysis with HR of 3.4 (95\% CI: 1.4-8.4, $p=0.005$ ) and 2.8 (95\% CI: 1.3-6.3, $p=0.010$ ), respectively. Grade of tumor lost its statistical significance in multivariate analysis.

\section{Pattern of Recurrence and Salvage Treatment}

Status of disease progression was documented in 275 patients. At a median follow-up of 32.4 months, 130 patients experienced disease progression. Most common pattern of recurrence was local but $9(6.9 \%)$ patients had leptomeningeal dissemination. Details of salvage therapy were available in 76 (58.5\%) patients. About 26.3\% patients underwent a repeat surgery alone, and $17.1 \%$ patients received radiation as salvage treatment. However, a total of 54 (71.1\%) patients underwent surgery followed by observation or other form of therapy as well. Of these 76 patients, 51 (67.1\%) received radiation either alone or in combination with surgery and chemotherapy. Interestingly, only 5 of these 51 patients had received prior radiation. Salvage chemotherapy has been used in 30 (39.5\%) patients. Chemotherapy regimen varied widely from temozolomide, bevacizumab, carmustine, lapatinib, irinotecan, flutamide, lomustine, cyclophosphamide, 


\section{Progression Free Survival}
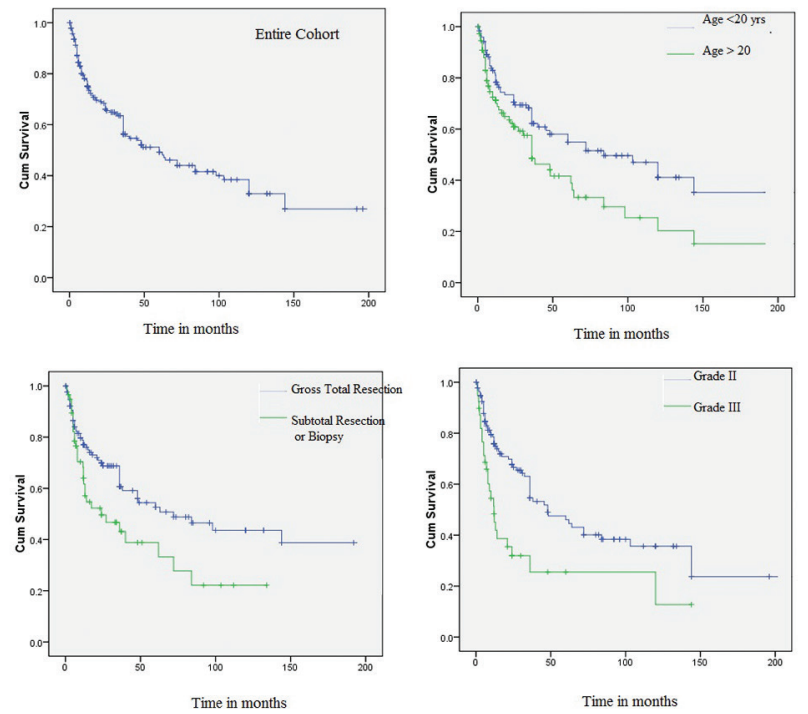

Fig. 2 Kaplan-Meier curves showing progression-free survival in patients with xanthoastrocytoma for entire cohort, with respect to age, nature of surgery, and grade of tumor.

\section{Overall Survival}
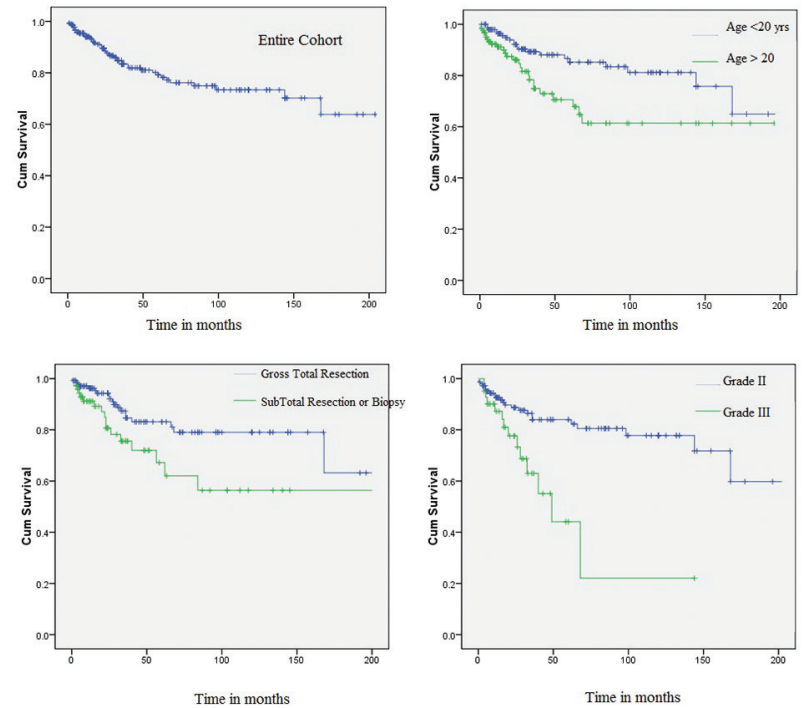

Fig. 3 Kaplan-Meier curves showing overall survival in patients with xanthoastrocytoma for entire cohort, with respect to age, nature of surgery, and grade of tumor.

thiotepa, dabrafenib, etc. Interestingly, 4 patients were diagnosed with astrocytoma, glioblastoma, or anaplastic oligodendroglioma at recurrence.

\section{Discussion}

XA has long been considered an indolent tumor entity. Because of the rarity of this tumor, there is a paucity of data regarding its clinical behavior and dilemma regarding the optimum treatment of these patients. In the absence of level
I evidence, the individual patient data analysis was formulated to describe the demography, pattern of care, and survival outcome for XA. The survival and prognostic variables for Grade II XA has already been described in an earlier article. ${ }^{1}$ Hence, the present article aimed to compare survival and prognostic factors for Grade III XA with that of Grade II tumors as well. We retrieved 138 publications and derived individual patient data of 325 odd patients for the purpose of the analysis. Interestingly, only 7 publications had a sample size of more than 10 .

For the entire cohort of XA, median age was 19 years. Our previous analysis of Grade II XA highlights the median age of 20 years which is not different for the entire cohort as well. This clearly reflects that XA is predominantly a disease of the young adults. The present analysis revealed an impressive median OS of 209 months for Grade II tumors, while it was only 49 months for Grade III tumors. An earlier analysis of Grade II and Grade III XA reported similar median survival. ${ }^{139}$ Univariate analysis also pointed toward a better prognostic outcome for older patients ( $>20$ years) compared with the younger patients ( $<20$ years). Eighty-two percent of the cases are diagnosed up to the age of 40 years with isolated cases in different ages beyond 40 years.

A Surveillance, Epidemiology, and End Results (SEER) data analysis and our previous analysis highlight the importance of surgery in particular importance of achieving a GTR. ${ }^{139}$ Although, in multivariate analysis, extent of surgery was not significant in the SEER analysis, it was significant in the analysis for Grade II tumors. The most important limitation of interpreting the surgical extent is variation of surgeons, different centers with variable experience, and in long period ways of interpretation of completeness of surgery. In addition, surgical standards have improved over the last few years with modern techniques such as intraoperative magnetic resonance imaging (MRI), awake craniotomy, and postoperative MRI. With the limitations of all these variables, the present analysis revealed significant impact of a GTR both on PFS (HR $2.19, p=0.019$ ) and OS (HR 1.72, $p=0.017$ ). These findings clearly highlight the importance of achieving a GTR in XA. The analysis also highlights the importance of referring such patients to a center with expertise for better management.

However, the impact of adjuvant radiation was not a significant factor influencing OS or PFS. However, point should also be made that many of the patients have received radiation in poor performance status or with a large tumor. Furthermore, a possibility of publication bias cannot be ignored. This also highlights adopting a risk adopted treatment approach for lower and higher grade tumors. Hence, a GTR should be optimum for a lower grade tumor but a higher grade tumor merits more aggressive therapy with adjuvant radiotherapy or a combination of radiotherapy and chemotherapy should be advocated.

Because of excellent treatment outcome, long-term squeal and neurocognitive function is very important for these patients and every effort should be made to assure a better quality of life for patients with XA. In addition, follow-up protocol should also be carefully designed. As local recurrence is predominant, a contrast-enhanced MRI of brain 
every 3 months for the first 3 years and thereafter 6 monthly for 2 years and then annually should be optimum.

In the recent years, great enthusiasm has been witnessed in exploring the molecular pattern of XA. Different reports have demonstrated nearly V600E BRAF mutation in nearly $70 \%$ patients which constitutively activates RAS/RAF/MEK/ ERK signaling pathway. Different BRAF inhibitors such as vemurafenib and dabrafenib have shown promising results in the management of recurrent XA. The present analysis revealed 58\% BRAF mutation rate which makes it an interesting target for recurrent cases.

The analysis reveals many important facts about the rare tumor. We found significantly improved survival outcome for patients treated with a GTR than those with STR. Similarly, both PFS and OS favored patients with a Grade II tumor, younger age. However, the impact of adjuvant therapy was not clearly beneficial. Note should be made that nearly 47.7\% patients experience disease progression at a median follow-up of nearly 3 years. Hence, risk stratification should be done and adjuvant radiation and chemotherapy may be advocated for high-risk patients.

This analysis has few limitations as well. As the individual patient data has been extracted from publication over a long period of time, a temporal bias is paramount importance. In this time frame, diagnostic criteria, surgical skill, and treatment approach have changed which may have definite impact on the quality of report. In addition, the publications included in the analysis are retrospective which also add to different types of bias. Because of inhomogeneity in reporting the cases, all relevant data pertaining to each case were not retrieved. This also forced us to conduct analysis on available fraction of data for fewer parameters. The use of individual patient characteristics for analysis may be considered as one of the merits of this work.

\section{Conclusion}

$\mathrm{XA}$ is a disease of young adults with favorable prognosis. Younger patients ( $<20$ years), patients who undergo a GTR, and patients with a lower grade tumor have a better treatment outcome. The role of adjuvant therapy is debatable. However, in Grade III and incompletely resected tumors, adjuvant radiation of a combination of both radiotherapy and chemotherapy should be delivered. Whole genome sequencing should be performed to identify patients with different clinical behavior and treat accordingly.

\section{Funding}

None.

\section{Conflict of Interest}

None declared.

\section{References}

1 Mallick S, Benson R, Melgandi W, Giridhar P, Rath GK. Grade II pleomorphic xanthoastrocytoma; a meta-analysis of data from previously reported 167 cases. J Clin Neurosci 2018;54:57-62

2 Hamlat A, Le Strat A, Guegan Y, Ben-Hassel M, Saikali S. Cerebellar pleomorphic xanthoastrocytoma: case report and literature review. Surg Neurol 2007;68(1):89-94, discussion 94-95

3 Adeleye AO, Okolo CA, Akang EE, Adesina AM. Cerebral pleomorphic xanthoastrocytoma associated with NF1: an updated review with a rare atypical case from Africa. Neurosurg Rev 2012;35(3):313-319, discussion 319

4 Aisner DL, Newell KL, Pollack AG, et al. Composite pleomorphic xanthoastrocytoma-epithelioid glioneuronal tumor with BRAF V600E mutation - report of three cases. Clin Neuropathol 2014;33(2):112-121

5 Alexandrescu S, Korshunov A, Lai SH, et al. Epithelioid glioblastomas and anaplastic epithelioid pleomorphic xanthoastrocytomas - same entity or first cousins? Brain Pathol 2016;26(2):215-223

6 Alexiou GA, Moschovi M, Stefanaki K, Prodromou C, Sfakianos G, Prodromou N. Malignant progression of a pleomorphic xanthoastrocytoma in a child. Neuropediatrics 2010;41(2):69-71

7 Arita K, Kurisu K, Tominaga A, Sugiyama K, Sumida M, Hirose T. Intrasellar pleomorphic xanthoastrocytoma: case report. Neurosurgery 2002;51(4):1079-1082, discussion 1082

8 Asano K, Miyamoto S, Kubo O, Kikkukawa T, Yagihashi A, Ohkuma H. A case of anaplastic pleomorphic xanthoastrocytoma presenting with tumor bleeding and cerebrospinal fluid dissemination. Brain Tumor Pathol 2006;23(1):55-63

9 Bayindir C, Balak N, Karasu A, Kasaroğlu D. Anaplastic pleomorphic xanthoastrocytoma. Childs Nerv Syst 1997;13(1):50-56

10 Benjamin C, Faustin A, Snuderl M, Pacione D. Anaplastic pleomorphic xanthoastrocytoma with spinal leptomeningeal spread at the time of diagnosis in an adult. J Clin Neurosci 2015;22(8):1370-1373

11 Binesh F, Akhavan A, Navabii H. Pleomorphic xanthoastrocytoma with malignant transformation and multiple recurrences in an Iranian girl. BMJ Case Rep 2012

12 Bleggi-Torres LF, Gasparetto EL, Faoro LN, et al. Pleomorphic xanthoastrocytoma: report of a case diagnosed by intraoperative cytopathological examination. Diagn Cytopathol 2001;24(2):120-122

13 Brown NF, Carter T, Mulholland P. Dabrafenib in BRAFV600-mutated anaplastic pleomorphic xanthoastrocytoma. CNS Oncol 2017;6(1):5-9

14 Bucciero A, De Caro MI, Tedeschi E, et al. Atypical pleomorphic xanthoastrocytoma. J Neurosurg Sci 1998;42(3):153-157

15 Chacko G, Chacko AG, Dunham CP, Judkins AR, Biegel JA, Perry A. Atypical teratoid/rhabdoid tumor arising in the setting of a pleomorphic xanthoastrocytoma. J Neurooncol 2007;84(2):217-222

16 Chakrabarty A, Mitchell P, Bridges LR, Franks AJ. Malignant transformation in pleomorphic xanthoastrocytoma-a report of two cases. Br. J Neurosurg 1999;13(5):516-519

17 Chamberlain MC. Salvage therapy with BRAF inhibitors for recurrent pleomorphic xanthoastrocytoma: a retrospective case series. J Neurooncol 2013;114(2):237-240

18 Chang HT, Latorre JG, Hahn S, Dubowy R, Schelper RL. Pediatric cerebellar pleomorphic xanthoastrocytoma with anaplastic features: a case of long-term survival after multimodality therapy. Childs Nerv Syst 2006;22(6):609-613

19 Chapman EM, Ranger A, Lee DH, Hammond RR. A 15 year old boy with a posterior fossa tumor. Brain Pathol 2009;19(2):349-352

20 Charbel FT. Pleomorphic xanthoastrocytoma with malignant progression. Surg Neurol 1998;50(4):385-386

21 Choudry UK, Khan SA, Qureshi A, Bari E. Primary anaplastic pleomorphic xanthoastrocytoma in adults. Case report and review of literature. Int J Surg Case Rep 2016;27:183-188

22 Cicuendez M, Martinez-Saez E, Martinez-Ricarte F. Asanza EC, Sahuquillo J. Combined pleomorphic xanthoastrocytoma-ganglioglioma with BRAF V600E mutation: case report. J Neurosurg Pediatr 2016;18(1):53-57 
23 Das S, Yip S, Hukin J, Cochrane D, Dunham C. Pleomorphic xanthoastrocytoma of the spinal cord: case report and literature review. Clin Neuropathol 2014;33(3):190-196

24 de Tella OI, Jr. Herculano MA, Prandini MN, Stavale JN, Aguiar $\mathrm{PH}$. Malignant transformation of pleomorphic xanthoastrocytoma: case report. Arq Neuropsiquiatr 2003;61(1):104-106

25 Ebato M, Tsunoda A, Maruki C, Ikeya F, Okada M. Distinctive pleomorphic xanthoastrocytoma-like tumor with exclusive abortive or aberrant neuronal differentiation and repeated recurrence-case report. Neurol Med Chir (Tokyo) 2002;42(9):399-405

26 Etzl MM, Jr. Kaplan AM, Moss SD, et al. Positron emission tomography in three children with pleomorphic xanthoastrocytoma. J Child Neurol 2002;17(7):522-527

27 Evans AJ, Fayaz I, Cusimano MD, Laperriere N, Bilbao JM. Combined pleomorphic xanthoastrocytoma-ganglioglioma of the cerebellum. Arch Pathol Lab Med 2000;124(11):1707-1709

28 Foo J, Ng WH. Metastatic pleomorphic xanthoastrocytoma in the scalp. J Clin Neurosci 2011;18(4):565-567

29 Fouladi M, Jenkins J, Burger P, et al. Pleomorphic xanthoastrocytoma: favorable outcome after complete surgical resection. Neuro-oncol 2001;3(3):184-192

30 Frank S, Cordier D, Tolnay M, Rosenblum MKA. A 28-year-old man with headache, visual and aphasic speech disturbances. Brain Pathol 2009;19(1):163-166

31 Fu YJ, Miyahara H, Uzuka T, et al. Intraventricular pleomorphic xanthoastrocytoma with anaplastic features. Neuropathology 2010;30(4):443-448

32 Furuta A, Takahashi H, Ikuta F, Onda K, Takeda N, Tanaka R. Temporal lobe tumor demonstrating ganglioglioma and pleomorphic xanthoastrocytoma components. Case report. J Neurosurg 1992;77(1):143-147

33 Gelpi E, Popovic M, Preusser M, Budka H, Hainfellner J. Pleomorphic xanthoastrocytoma with anaplastic features presenting without GFAP immunoreactivity: implications for differential diagnosis. Neuropathology 2005;25(3):241-246

34 Gill M, Pathak HC, Madan R, Bhattacharya S, Choudhary GS. Primary spinal pleomorphic xanthoastrocytoma. Neurol India 2010;58(5):771-773

35 Glasser RS, Rojiani AM, Mickle JP, Eskin TA. Delayed occurrence of cerebellar pleomorphic xanthoastrocytoma after supratentorial pleomorphic xanthoastrocytoma removal. Case report. J Neurosurg 1995;82(1):116-118

36 Goldring S, Rich KM, Picker S. Experience with gliomas in patients presenting with a chronic seizure disorder. Clin Neurosurg 1986;33:15-42

37 Gonçalves VT, Reis F, Queiroz LdeS, França M, Jr. Pleomorphic xanthoastrocytoma: magnetic resonance imaging findings in a series of cases with histopathological confirmation. Arq Neuropsiquiatr 2013;71(1):35-39

38 Gupta RK, Saran RK, Sharma MC, Srivastava AK, Garg L. Melanosomal melanin pigment in pleomorphic xanthoastrocytoma, evidence for neuronal-glial origin: a case report with review of the literature. Neuropathology 2017;37(2):116-121

39 Hashmi M, Jaffari AA, Siddiqi SA, et al. Pleomorphic xanthoastrocytoma: an atypical astrocytoma. J Pak Med Assoc 2012;62(2):175-177

40 Hattab EM, Martin SE, Shapiro SA, Cheng L. Pleomorphic xanthoastrocytoma and oligodendroglioma: collision of 2 morphologically and genetically distinct anaplastic components. J Neurosurg 2011;114(6):1648-1653

41 Herpers MJ, Freling G, Beuls EA. Pleomorphic xanthoastrocytoma in the spinal cord. Case report. J Neurosurg 1994;80(3):564-569

42 Hirose T, Ishizawa K, Sugiyama K, Kageji T, Ueki K, Kannuki S. Pleomorphic xanthoastrocytoma: a comparative pathological study between conventional and anaplastic types. Histopathology 2008;52(2):183-193
43 Hong CS, Wang JL, Dornbos D, III. Joehlin-Price A, Elder JB. BRAF-mutated pleomorphic xanthoastrocytoma of the spinal cord with eventual anaplastic transformation. World Neurosurg 2017;98:871.e9-871.e15

44 Horiguchi S, Mitsuya K, Watanabe R, Yagishita S, Nakasu Y. Pleomorphic xanthoastrocytoma and moyamoya disease in a patient with neurofibromatosis type 1 - case report. Neurol Med Chir (Tokyo) 2011;51(4):310-314

45 Im SH, Chung CK, Kim SK, Cho BK, Kim MK, Chi JG. Pleomorphic xanthoastrocytoma: a developmental glioneuronal tumor with prominent glioproliferative changes. J Neurooncol 2004;66(1-2):17-27

46 Iwaki T, Fukui M, Kondo A, Matsushima T, Takeshita I. Epithelial properties of pleomorphic xanthoastrocytomas determined in ultrastructural and immunohistochemical studies. Acta Neuropathol 1987;74(2):142-150

47 Jea A, Ragheb J, Morrison G. Unique presentation of pleomorphic xanthoastrocytoma as a lytic skull lesion in an eight-yearold girl. Pediatr Neurosurg 2002;37(5):254-257

48 Jeong JY, Suh YL, Hong SW. Atypical teratoid/rhabdoid tumor arising in pleomorphic xanthoastrocytoma: a case report. Neuropathology 2014;34(4):398-405

49 Jiang GY, Yu JH, Zhang XY, Qi XL, Sun YS. Pleomorphic xanthoastrocytoma arising from the suprasellar region: a report of two cases. J Clin Neurosci 2016;33:228-231

50 Jiang YF, Liu Y, Wang YL, et al. Angiomatous pleomorphic xanthoastrocytoma: a case report and literature review. Diagn Pathol 2016;11(1):73

51 Jiménez-Heffernan JA, Freih Fraih A, Álvarez F, Bárcena C, Corbacho C. Cytologic features of pleomorphic xanthoastrocytoma, WHO grade II. A comparative study with glioblastoma. Diagn Cytopathol 2017;45(4):339-344

52 Kaku MV, Bhat DI, Shukla D, Mahadevan A, Devi BI. Pleomorphic xanthoastrocytoma arising from olfactory groove: a rare location for a rare tumor. Pediatr Neurosurg 2013;49(5):292-296

53 Katayama K, Asano K, Shimamura N, et al. Case of pleomorphic xanthoastrocytoma with anaplastic features in the pineal gland. Brain Tumor Pathol 2013;30(4):242-246

54 Kepes JJ, Rubinstein LJ, Ansbacher L, Schreiber DJ. Histopathological features of recurrent pleomorphic xanthoastrocytomas: further corroboration of the glial nature of this neoplasm. A study of 3 cases. Acta Neuropathol 1989;78(6):585-593

55 Kim B, Chung CK, Myung JK, Park SH. Pleomorphic xanthoastrocytoma associated with long-standing Taylor-type IIB-focal cortical dysplasia in an adult. Pathol Res Pract 2009;205(2):113-117

56 Koga T, Morita A, Maruyama K, et al. Long-term control of disseminated pleomorphic xanthoastrocytoma with anaplastic features by means of stereotactic irradiation. Neuro-oncol 2009;11(4):446-451

57 Kordek R, Biernat W, Alwasiak J, Liberski PP. Pleomorphic xanthoastrocytoma and desmoplastic infantile gangliogliomahave these neoplasms a common origin? Folia Neuropathol 1994;32(4):237-239

58 Krossnes BK, Mella O, Wester K, Mørk SJ. Pigmented astrocytoma with suprasellar location: case report and literature review. Acta Neuropathol 2004;108(5):461-466

59 Kumar S, Retnam TM, Menon G, Nair S, Bhattacharya RN, Radhakrishnan VV. Cerebellar hemisphere, an uncommon location for pleomorphic xanthoastrocytoma and lipidized glioblastoma multiformis. Neurol India 2003;51(2):246-247

60 Kurschel S, Lellouch-Tubiana A, Kulkarni AV, Sainte-Rose C. Pleomorphic xanthoastrocytoma of the cerebellopontine angle in a child. Childs Nerv Syst 2006;22(11):1479-1482

61 Lach B, Duggal N, DaSilva VF, Benoit BG. Association of pleomorphic xanthoastrocytoma with cortical dysplasia and neuronal tumors. A report of three cases. Cancer 1996;78(12):2551-2563 
62 Lacoste-Collin L, d'Aure D, Aziza J, Quintyn ML, Uro-Coste E, Courtade-Saïdi M. Cerebrospinal fluid cytologic findings of a pleomorphic xanthoastrocytoma: a case report. Acta Cytol 2010;54(5, Suppl):871-874

63 Lee EQ, Ruland S, LeBoeuf NR, Wen PY, Santagata S. Successful treatment of a progressive BRAF V600E-mutated anaplastic pleomorphic xanthoastrocytoma with vemurafenib monotherapy. J Clin Oncol 2016;34(10):e87-e89

64 Leonard N, Alcutt DA, Farrell MA. Fatal pleomorphic xanthoastrocytoma with meningeal gliomatosis. Histopathology 1998;32(4):375-378

65 Lim S, Kim JH, Kim SA, Park ES, Ra YS, Kim CJ. Prognostic factors and therapeutic outcomes in 22 patients with pleomorphic xanthoastrocytoma. J Korean Neurosurg Soc 2013;53(5):281-287

66 Lim SC, Jang SJ, Kim YS. Cerebellar pleomorphic xanthoastrocytoma in an infant. Pathol Int 1999;49(9):811-815

67 Lindboe CF, Cappelen J, Kepes JJ. Pleomorphic xanthoastrocytoma as a component of a cerebellar ganglioglioma: case report. Neurosurgery 1992;31(2):353-355

68 Lubansu A, Rorive S, David P, et al. Cerebral anaplastic pleomorphic xanthoastrocytoma with meningeal dissemination at first presentation. Childs Nerv Syst 2004;20(2):119-122

69 Macaulay RJ, Jay V, Hoffman HJ, Becker LE. Increased mitotic activity as a negative prognostic indicator in pleomorphic xanthoastrocytoma. Case report. J Neurosurg 1993;79(5):761-768

70 Martin AG, Singh MS, Idris B, Abdullah JM. Pleomorphic xanthoastrocytoma in a case of tuberous sclerosis. J Neurosci Rural Pract 2014;5(3):258-260

71 Marton E, Feletti A, Orvieto E, Longatti P. Malignant progression in pleomorphic xanthoastrocytoma: personal experience and review of the literature. J Neurol Sci 2007;252(2):144-153

72 Mascalchi M, Muscas GC, Galli C, Bartolozzi C. MRI of pleomorphic xanthoastrocytoma: case report. Neuroradiology 1994;36(6):446-447

73 McNatt SA, Gonzalez-Gomez I, Nelson MD, McComb JG. Synchronous multicentric pleomorphic xanthoastrocytoma: case report. Neurosurgery 2005;57(1):E191

74 Menendez R, Fernandez J, Monti A, Sevlever G. Intraventricular pleomorphic xanthoastrocytoma: a case report. Turk Neurosurg 2014;24(6):987-991

75 Miyagi Y, Suzuki SO, Iwaki T, et al. Pleomorphic xanthoastrocytoma with predominantly exophytic growth: case report. Surg Neurol 2001;56(5):330-332

76 Montano N, Papacci F, Cioni B, et al. Primary multicentric anaplastic pleomorphic xanthoastrocytoma with atypical features. J Clin Neurosci 2013;20(11):1605-1608

77 Moore W, Mathis D, Gargan L, et al. Pleomorphic xanthoastrocytoma of childhood: MR imaging and diffusion MR imaging features. AJNR Am J Neuroradiol 2014;35(11):2192-2196

78 Nagańska E, Matyja E, Pucko E, Ząbek M. The coexistence of pleomorphic xanthoastrocytoma and arteriovenous malformation. A case report. Folia Neuropathol 2013;51(3):269-274

79 Naidich MJ, Walker MT, Gottardi-Littell NR. Han G, Chandler JP. Cerebellar pleomorphic xanthoastrocytoma in a patient with neurofibromatosis type 1. Neuroradiology 2004;46(10):825-829

80 Nakajima T, Kumabe T, Shamoto H, Watanabe M, Suzuki H, Tominaga T. Malignant transformation of pleomorphic xanthoastrocytoma. Acta Neurochir (Wien) 2006;148(1):67-71

81 Nakamura M, Chiba K, Matsumoto M, Ikeda E, Toyama Y. Pleomorphic xanthoastrocytoma of the spinal cord. Case report. J Neurosurg Spine 2006;5(1):72-75

82 Nasuha NA, Daud AH, Ghazali MM, et al. Molecular genetic analysis of anaplastic pleomorphic xanthoastrocytoma. Asian J Surg 2003;26(2):120-125
83 Neal MT, Ellis TL, Stanton CA. Pleomorphic xanthoastrocytoma in two siblings with neurofibromatosis type 1 (NF-1) Clin Neuropathol 2012;31(1):54-56

84 Nern C, Hench J, Fischmann A. Spinal imaging in intracranial primary pleomorphic xanthoastrocytoma with anaplastic features. J Clin Neurosci 2012;19(9):1299-1301

$85 \mathrm{Ng} \mathrm{WH}$, Lim T, Yeo TT. Pleomorphic xanthoastrocytoma in elderly patients may portend a poor prognosis. J Clin Neurosci 2008;15(4):476-478

86 Niamathullah S, Sivaselvam S, Ghosh M, Ghosh S. Pleomorphic xanthoastrocytoma with anaplastic features: a case report. Indian J Pathol Microbiol 2014;57(1):101-104

87 Oh T, Kaur G, Madden M, Bloch O, Parsa AT. Pleomorphic xanthoastrocytomas: institutional experience of 18 patients. J Clin Neurosci 2014;21(10):1767-1772

88 Okazaki T, Kageji T, Matsuzaki K, et al. Primary anaplastic pleomorphic xanthoastrocytoma with widespread neuroaxis dissemination at diagnosis-a pediatric case report and review of the literature. J Neurooncol 2009;94(3):431-437

89 Passone E, Pizzolitto S, D’Agostini S, et al. Non-anaplastic pleomorphic xanthoastrocytoma with neuroradiological evidences of leptomeningeal dissemination. Childs Nerv Syst 2006;22(6):614-618

90 Patibandla MR, Nayak M, Purohit AK, Thotakura AK, Uppin M, Challa S. Pleomorphic xanthoastrocytoma with anaplastic features: a rare case report and review of literature with reference to current management. Asian J Neurosurg 2016;11(3):319

91 Paulus W, Lisle DK, Tonn JC, et al. Molecular genetic alterations in pleomorphic xanthoastrocytoma. Acta Neuropathol 1996;91(3):293-297

92 Perry A, Giannini C, Scheithauer BW, et al. Composite pleomorphic xanthoastrocytoma and ganglioglioma: report of four cases and review of the literature. Am J Surg Pathol 1997;21(7):763-771

93 Perry A, Scheithauer BW, Szczesniak DM, Atkinson JL, Wald JT, Hammak JE. Combined oligodendroglioma/pleomorphic xanthoastrocytoma: a probable collision tumor: case report. Neurosurgery 2001;48(6):1358-1361

94 Prayson RA. Pleomorphic xanthoastrocytoma arising in neurofibromatosis Type 1. Clin Neuropathol 2012;31(3):152-154

95 Ramelli GP, von der Weid N, Remonda L, Mariani L, Weis J. Pleomorphic xanthoastrocytoma derived from glioneuronal malformation in a child with intractable epilepsy. J Child Neurol 2000;15(4):270-272

96 Rao AA, Laack NN, Giannini C, Wetmore C. Pleomorphic xanthoastrocytoma in children and adolescents. Pediatr Blood. Cancer 2010;55(2):290-294

97 Razzaq AA, Akula M, Mathew B. Unusual recurrence of pleomorphic xanthoastrocytoma. Br. J Neurosurg 2006;20(6):433-434

98 Hessler RB, Kfoury H, Al-Watban J, Hassounah M. Angiomatous pleomorphic xanthoastrocytoma as a component of ganglioglioma. Ann Saudi Med 1999;19(1):48-51

99 Rosemberg S, Rotta JM, Yassuda A, Velasco O, Leite CC. Pleomorphic xanthoastrocytoma of the cerebellum. Clin Neuropathol 2000;19(5):238-242

100 Rutkowski MJ, Oh T, Niflioglu GG, Safaee M, Tihan T, Parsa AT. Pleomorphic xanthoastrocytoma with anaplastic features: retrospective case series. World Neurosurg 2016;95:368-374

101 Saikali S, Le Strat A, Heckly A, Stock N, Scarabin JM, Hamlat A. Multicentric pleomorphic xanthoastrocytoma in a patient with neurofibromatosis type 1 . Case report and review of the literature. J Neurosurg 2005;102(2):376-381

102 Sawyer JR, Roloson GJ, Chadduck WM, Boop FA. Cytogenetic findings in a pleomorphic xanthoastrocytoma. Cancer Genet Cytogenet 1991;55(2):225-230 
103 Sezer S, Baykan A, Yilmaz E, et al. Atrial fibrillation as an uncommon presentation in a large pleomorphic xanthoastrocytoma. Childs Nerv Syst 2012;28(3):475-479

104 Sharma M, Chaudhery S, Sonig A, Ambekar S, Nanda A. Does the occurrence of pleomorphic xanthoastrocytoma in the elderly carries a poor prognosis: a case report and review of literature. Asian J Neurosurg 2014;9(4):237

105 Sharma MC, Arora R, Khanna N, Singh VP, Sarkar C. Pigmented pleomorphic xanthoastrocytoma: report of a rare case with review of the literature. Arch Pathol Lab Med 2001;125(6):808-811

106 Simal-Julián JA, Sanchis-Martín R, Prat-Acín R, et al. Spinal pleomorphic xanthoastrocytoma. Case report [in Spanish]. Neurocirugia (Astur) 2010;21(5):390-395

107 Srinivas BH, Uppin MS, Panigrahi MK. Vijaya Saradhi M, Jyotsna Rani Y, Challa S. Pleomorphic xanthoastrocytoma of the pineal region. J Clin Neurosci 2010;17(11):1439-1441

108 Stuart G, Appleton DB, Cooke R. Pleomorphic xanthoastrocytoma: report of two cases. Neurosurgery 1988;22(2):422-427

109 Sugita Y, Irie K, Ohshima K, Hitotsumatsu T, Sato O, Arimura K. Pleomorphic xanthoastrocytoma as a component of a temporal lobe cystic ganglioglioma: a case report. Brain Tumor Pathol 2009;26(1):31-36

110 Sugita Y, Shigemori M, Okamoto K, Morimatsu M, Arakawa M, Nakayama K. Clinicopathological study of pleomorphic xanthoastrocytoma: correlation between histological features and prognosis. Pathol Int 2000;50(9):703-708

111 Sundaram C, Naidu MR, Reddy JJ. Pleomorphic xanthoastrocytoma-a clinicopathological study. Indian J Pathol Microbiol 2000;43(3):357-361

112 Suzuki Y, Akiyama Y, Kimura Y, Sugita S, Hasegawa T, Mikuni N. Pleomorphic xanthoastrocytoma with anaplastic features in the Tectal region in a young adult patient: a case report. World Neurosurg 2016;94:580.e11-580.e15

113 Takei H, Rouah E, Bhattacharjee MB. Cerebellar pleomorphic xanthoastrocytoma in a patient with neurofibromatosis type 1: a case report and literature review. Int J Clin Exp Pathol 2015;8(6):7570-7574

114 Tan TC, Ho LC, Yu CP, Cheung FC. Pleomorphic xanthoastrocytoma: report of two cases and review of the prognostic factors. J Clin Neurosci 2004;11(2):203-207

115 Tonn JC, Paulus W, Warmuth-Metz M, Schachenmayr W, Sörensen N, Roosen K. Pleomorphic xanthoastrocytoma: report of six cases with special consideration of diagnostic and therapeutic pitfalls. Surg Neurol 1997;47(2):162-169

116 Tsutsumi S, Abe Y, Yasumoto Y, Ito M. Anaplastic pleomorphic xanthoastrocytoma with a component of anaplastic astrocytoma presenting as skull base tumor followed by downward extracranial extension. Case report. Neurol Med Chir (Tokyo) 2010;50(12):1108-1112

117 Tsuyuguchi N, Matsuoka Y, Sunada I, Matsusaka Y, Haque M. Evaluation of pleomorphic xanthoastrocytoma by use of positron emission tomography with. AJNR Am J Neuroradiol 2001;22(2):311-313

118 Usubalieva A, Pierson CR, Kavran CA, et al. Primary meningeal pleomorphic xanthoastrocytoma with anaplastic features: a report of 2 cases, one with BRAF(V600E) mutation and clinical response to the BRAF inhibitor dabrafenib. J Neuropathol. Exp Neurol 2015;74(10):960-969

119 Vajtai I, Stibal A, von Gunten M, Kappeler A, Vassella E, Frank S. Glycogen-rich pleomorphic xanthoastrocytoma with clear-cell features: confirmatory report of a rare variant with implications for differential diagnosis. Pathol Res Pract 2011;207(4):256-261

120 Vajtai I, Varga Z, Aguzzi A. Pleomorphic xanthoastrocytoma with gangliogliomatous component. Pathol Res Pract 1997;193(9):617-621
121 van Roost D, Kristof R, Zentner J, Wolf HK, Schramm J. Clinical, radiological, and therapeutic features of pleomorphic xanthoastrocytoma: report of three patients and review of the literature. J Neurol Neurosurg Psychiatry 1996;60(6):690-692

122 Vizcaíno MA, Caccamo DV, Fox E, Rodriguez FJ. Pleomorphic xanthoastrocytoma: report of two cases with unconventional clinical presentations. Clin Neuropathol 2014;33(6):380-387

$123 \mathrm{Vu}$ TM, Liubinas SV, Gonzales M, Drummond KJ. Malignant potential of pleomorphic xanthoastrocytoma. J Clin Neurosci 2012;19(1):12-20

124 Wallace DJ, Byrne RW, Ruban D, Cochran EJ, Roh D, Whisler WW. Temporal lobe pleomorphic xanthoastrocytoma and chronic epilepsy: long-term surgical outcomes. Clin Neurol Neurosurg 2011;113(10):918-922

125 Wasdahl DA, Scheithauer BW, Andrews BT, Jeffrey RA, Jr. Cerebellar pleomorphic xanthoastrocytoma: case report. Clin Neuropathol 2000;19:238-242

126 Whittle IR, Gordon A, Misra BK, Shaw JF, Steers AJ. Pleomorphic xanthoastrocytoma. Report of four cases. J Neurosurg 1989;70(3):463-468

127 Wind JJ, Kerr PB, Sweet JA, Deshmukh VR. Pleomorphic xanthoastrocytoma presenting with life-threatening hemorrhage in a child. J Neurosurg Pediatr 2009;3(2):157-159

128 Xiong J, Chu SG, Mao Y, Wang Y. Pigmented pleomorphic xanthoastrocytoma: a rare variant and literature review. Neuropathology 2011;31(1):88-92

129 Yamada SM, Murakami H, Tomita Y, et al. Glioblastoma multiforme versus pleomorphic xanthoastrocytoma with anaplastic features in the pathological diagnosis: a case report. Diagn Pathol 2016;11(1):65

130 Yang MM, Singhal A, Rassekh SR, Yip S, Eydoux P, Dunham C. Possible differentiation of cerebral glioblastoma into pleomorphic xanthoastrocytoma: an unusual case in an infant. J Neurosurg Pediatr 2012;9(5):517-523

131 Yang WQ Huang B, Liang CH. Pleomorphic xanthoastrocytoma in the lateral ventricle with extensive subarachnoid dissemination: report of a case and review of the literature. Chin Med J (Engl) 2012;125(2):396-399

132 Yeh DJ, Hessler RB, Stevens EA, Lee MR. Composite pleomorphic xanthoastrocytoma-ganglioglioma presenting as a suprasellar mass: case report. Neurosurgery 2003;52(6):1465-1468, discussion 1468-1469

133 Yin XL, Hui AB, Liong EC, Ding M, Chang AR, Ng HK. Genetic imbalances in pleomorphic xanthoastrocytoma detected by comparative genomic hybridization and literature review. Cancer Genet Cytogenet 2002;132(1):14-19

134 Yoshikawa G, Kawamoto S, Yakou K, Tsutsumi K. Massive intracranial hemorrhage associated with pleomorphic xanthoastrocytoma-case report. Neurol Med Chir (Tokyo) 2010;50(3):220-223

135 Yu S, He L, Zhuang X, Luo B. Pleomorphic xanthoastrocytoma: MR imaging findings in 19 patients. Acta Radiol 2011;52(2):223-228

136 Zakrzewska M, Szybka M, Biernat W, et al. Prevalence of mutated TP53 on cDNA (but not on DNA template) in pleomorphic xanthoastrocytoma with positive TP53 immunohistochemistry. Cancer Genet Cytogenet 2009;193(2):93-97

137 Zhao X, Jiang X, Wang X. Spinal pleomorphic xanthoastrocytoma companied with periventricular tumor. Int J Clin Exp Pathol 2015;8(1):1036-1040

138 Zhuang Z, Lee YS, Zeng W, et al. Molecular genetic and proteomic analysis of synchronous malignant gliomas. Neurology 2004;62(12):2316-2319

139 Perkins SM, Mitra N, Fei W, Shinohara ET. Patterns of care and outcomes of patients with pleomorphic xanthoastrocytoma: a SEER analysis. J Neurooncol 2012;110(1):99-104 